\title{
Dependencia estratégica y no-estratégica: materias primas y relaciones internacionales en la perspectiva de la crisis petrolera
}

\author{
INTRODUCCIÓN
}

No hay duda de que la llamada "crisis petrolera" se ha transformado en el hecho más sobresaliente de los últimos años.

Como hecho económico se ha centrado en el rápido incremento del precio del petróleo comerciado internacionalmente y en serias restricciones de su abastecimiento. Las repercusiones de esta alza en los precios del hidrocarburo han alcanzado a la mayoría de los paises y han repercutido en los precios en general, en la producción, en el empleo, en las inversiones, en el consumo y en los balances de pagos. Representa un cambio radical en la distribución del ingreso en el mundo e intensifica el grave problema que ya existía antes en cuanto a la liquidez internacional. ${ }^{1}$

Como acontecimiento político, la crisis petrolera ha cuestionado la actual estructura del poder mundial. La crisis, en efecto, ha demostrado que los poderosos no eran tan fuertes ni los débiles tan frágiles. Asimismo, ha tenido un "efecto de demostración" para los países en vías de desarrollo que ya se han inspirado en el ejemplo árabe para negociar sus materias primas.

Sin embargo, la importancia mayor de la crisis para nuestros propósitos es que ha llegado a desafiar la mayoría de las previsiones e interpretaciones clásicas de las relaciones internacionales. Es decir, una serie de países "subdesarrollados" aliados en la OPEP se han transformado en una potencia revolucionaria que ha debilitado notablemente el "orden internacional legítimo" que pretendía construir el Secretario de Estado norteamericano Henry Kissinger. Por otra parte, mientras el desarrollo económico, científico y tecnológico de los países productores de petróleo no había experimentado cambio alguno, el poder de la OPEP - es decir el poder financiero derivado del alza de los precios del petróleo- alteraba fundamentalmente las principales estructuras del sistema internacional contemporáneo.

"Estudio Económico de América Latina 1973", CEPAL-Naciones Unidas (4 tomos), primera parte, pp. 36-39. 
De lo anterior se desprende que en este trabajo se pretenderá introducir nuevos elementos que nos ayuden a comprender la situación internacional emergida a raíz de los acontecimientos de octubre de 1973 (objetivos teóricos). Cabe precisar que no creemos que los países integrantes de la OPEP se vayan a transformar rápidamente en grandes potencias mundiales, o que como consecuencia de la crisis petrolera surgirá un nuevo orden político internacional definitivo y radicalmente distinto al anterior. En efecto, estamos seguros que dentro de alrededor de cinco años aparecerán nuevas fuentes de energía en reemplazo del petróleo. Por lo tanto, en una perspectiva a "largo plazo" parecería más importante el grado de madurez tecnológica que la mera posesión de reservas tales como el petróleo. ${ }^{2}$

No obstante, el problema a "corto y mediano plazo" persiste y abre múltiples interrogantes. De alli entonces que pretendamos examinar como la carencia de algunos recursos naturales importantes afecta la seguridad nacional de las potencias industrializadas y su posición en el sistema internacional.

Lo que la crisis del petróleo ha venido a demostrar entonces, es que el rol de algunas materias primas es de vital importancia para la seguridad nacional de los diversos países. Pero no se trata simplemente de que un país tenga o no tenga materias primas, sino que más bien interesa el "grado de dependencia" que el país tenga respecto de aquellas materias primas "claves" para el funcionamiento de su economía y/o para el mantenimiento y desarrollo de su industria bélica. De ahí que introduciremos el concepto "Dependencia Estratégica" -que pasaremos a definir más adelante- para identificar este tipo de situación.

El elevado grado de "dependencia estratégica" que experimentan varias naciones industrializadas se ve agudizada con la aparición de algunos carteles internacionales que se proponen utilizar sus recursos naturales conjuntamente como un arma de negociación frente a las grandes potencias.

Todo país con alto grado de "dependencia estratégica" deberá emprender una serie de "acciones internacionales" que le permita un acceso seguro a aquellos recursos escasos, o que motive el desarrollo de nuevas fuentes a través de la innovación científico-tecnológica.

Por otra parte, frente a la "dependencia estratégica" de los "pode-

'Por cjemplo, si bien Japón sufrió durante el embargo petrolero una humillación solamente comparable a la rendición durante la segunda guerra mundial y que significó una considcrable disminución de su status internacional, todavia cuenta con los elementos científicos-tecnológicos que pucden a la larga transformarle en una superpotencia del futuro como ha sostenido el futurólogo Herman Kahn. 
rosos" estará la oportunidad de los "débiles" organizados en organismos tales como la OPEP, el CIPEC y otros, de transformar las estructuras del comercio mundial y de establecer un nuevo orden económico internacional (objetivos prácticos del estudio).

En suma, la hipótesis principal de este trabajo es la siguiente: todos los países experimentan una situación de "dependencia estratégica" que se caracteriza por un mayor o menor déficit respecto de algunas materias primas claves, que se ve significativamente afectada por el accionar de los carteles de productores y que, a su vez, repercute en los diversos esquemas de seguridad de las naciones.

Ahora bien, como toda hipótesis debe estar ligada a un cuerpo de teoría hemos procedido a utilizar el marco teórico de la "dependencia". En este sentido, plantearemos que la marcada dependencia estratégica de muchos países industrializados equivale a lo que denominaremos una situación de "dependencia sectorial" que se contrapone con la "dependencia generalizada" de los países pobres, siendo ambos aspectos complementarios de una misma realidad. La formulación de la dependencia estratégica - que tenderá a identificarse con el mundo industrializado- no nos permite de ninguna manera plantear una situación de dependencia total por parte de los países ricos. A lo sumo podremos decir que los países industrializados experimentan una situación de "dependencia sectorial" y momentánea muy distinta a la "dependencia generalizada" tradicional de los países subdesarrollados.

Como podemos observar, este trabajo de investigación es eminentemente teórico lo que significa que nos evitaremos muchas de las limitaciones propias de estudios excesivamente empíricos.

Sin embargo, la investigación propuesta implica algunas restricciones que conviene destacar.

En primer lugar, el período en que se agudiza la situación a que nos hemos referido (crisis de octubre de 1973) es más bien reciente; de allí que quizás nos falte una perspectiva histórica adecuada. En cierto modo, algunos de los eventos estudiados están en pleno desarrollo.

En segundo término, hemos debido incursionar en campos ajenos a la especialidad de este investigador puesto que gran parte del estudio conlleva apreciaciones de carácter geológico y de otras materias afines.

Respecto al material bibliográfico debemos señalar que si bien existen limitaciones inmediatas propias de un país subdesarrollado como el nuestro, por lo menos aquél es adecuado y suficiente.

Finalmente, cabe señalar que esta versión escrita representa un primer esfuerzo en una investigación que recién comienza. Por lo 
tanto, debe ser considerada como un borrador preliminar, como un punto de partida de un proyecto más extenso que podría llegar a constituir un modesto aporte original.

MATERIAS PRIMAS Y RELACIONES INTERNACIONALES

\section{La importancia de las materias primas}

Decir que las materias primas - particularmente los minerales- son un importante factor de poder equivale a repetir algo quizás demasiado obvio. En efecto, parece ser que para que un país alcance un status de gran potencia debe contar con reservas adecuadas respecto de una serie de materias primas que podríamos denominar "claves".

Varios son los autores que han relacionado a los recursos naturales en general con el poder de una nación ${ }^{3}$. Hans Morgenthau, por ejemplo, sostiene que uno de los elementos importantes que conforman el poder nacional es justamente la variable "recursos naturales". 4

Morgenthau subdivide el factor recursos en: a) Alimentos y b) Materias primas. Respecto al primer elemento sostiene que un país que es autosuficiente posee una gran ventaja sobre aquél que no lo es y tiene que importar sus alimentos. Según el autor, la deficiencia en el automantenimiento alimentario habría sido uno de los factores permanentes de debilidad para Gran Bretaña y Alemania. Asimismo, la permanente escasez de alimentos sería un elemento de debilidad en la política internacional de India.

Lo mismo que sostiene acerca de los productos alimenticios lo aplica a aquellas materias primas esenciales para la producción de implementos bélicos.

Morgenthau afirma que la importancia de las materias primas en la determinación del poderío de una nación depende necesariamente de la técnica desplegada en un período determinado de la historia. Así, antes de la mecanización en gran escala de la guerra, cuando

${ }^{\text {s} W . ~ W . ~ K u l s k i, ~ " I n t e r n a t i o n a l ~ P o l i t i c s ~ i n ~ a ~ R e v o l u t i o n a r y ~ A g e " ~(P h i l a d e l-~}$ phia, Lippincott, 1968); Charles O. Lerke, Jr., y AbduI A. Said, "Concepts of International Politics" (Prentice-Hall, Englewood Cliffs, N. J., 1963) ; Hans Morgenthau, "Politics Among Nations" (Knopf, New York, 1961); A. F. K. Organski, "World Politics", 2nd ed. (Knopf, New York, 1968); Norman D. Palmer y Howard C. Perkins, "International Relations: The World Community in Transition" (Houghton-Mifflin, Boston, 1957); John G. Stoessinger, "The Might of Nations: World Politics in our Time", 3rd ed. (Random House, New York, 1969) .

${ }^{4}$ Hans Morgenthau, Ibid., pp. 110-149. 
los combates cuerpo a cuerpo constituían la técnica militar prevalente, otros factores (tales como la habilidad individual del soldado) eran más importantes que la posesión de materias primas para fabricar armamentos. Sin embargo, con el aumento de la mecanización de la guerra -especialmente a partir de la revolución industrial- el poder nacional pasa a depender cada vez más del control de las materias primas tanto en la guerra como en la paz.

La Segunda Guerra Mundial y el período que siguió a aquella ha demostrado en forma clara hasta que punto las materias del reino mineral constituyen la médula de la vida industrial y del desarrollo económico de las naciones en tiempos de paz. Las reservas que antiguamente parecian inagotables presentan ahora una importante merma, y los paises industrializados buscan cada vez más lejos aquellos productos minerales necesarios para su subsistencia. ${ }^{5}$

En las últimas dos décadas la escala global de la actividad económica prácticamente se ha triplicado. En 1950, los bienes y servicios producidos en el mundo valían un poco más de un trillón de dólares. A comienzos de la década del 70, valían cerca de 3 trillones. El efecto combinado de la explosión demográfica y el enorme aumento de la demanda de recursos ha motivado un crecimiento general del consumo que causa una duplicación de la economía global cada 16 a 18 años. Consecuentemente, la continua expansión de la actividad económica dependerá en gran parte de la cantidad de minerales y materias primas en general a disposición de los países ricos. ${ }^{6}$

Una ojeada a la historia de los grandes países industriales pone de manifiesto que su progreso coincidió con la utilización de sus recursos minerales. Pero, los países que primero se industrializaron están comenzando en algunos casos a agotar sus reservas locales de materias primas. Entre estos se cuentan la mayoría de los países de Europa Occidental y los EE. UU.

Japón -como veremos más adelante- clesde que comenzó su pro. ceso de industrialización ha dependido en gran medida de otros países para su abastecimiento de materias primas. Europa Occidental depende actualmente en un alto grado de importaciones para su abastecimiento de petróleo y de la mayoría de los otros minerales importantes.

Algunas reservas exportables de combustibles energéticos y materias primas están localizadas en países desarrollados tales como Ca-

${ }^{5}$ Aun considcrando los recursos no explotados en las regiones árticas y en los fondos occánicos, las reservas probadas de la mayoria de los minerales impor. tantes durarán solamente entre 10 y 50 años.

${ }^{\circ}$ Lester Brown, Rich Countries and Poor in a Finite and Interdependent World, en "Daedalus", Autumn 1973. 
nadá, Australia, Sudáfrica y la Unión Soviética, pero, paradojalmente, la mayoría de ellas están en los países en vías de desarrollo.

La gran parte de las reservas exportables de petróleo son controladas por la Organización de Países Exportadores de Petróleo (OPEP) conformada exclusivamente por países en desarrollo. Cuatro países pobres - Chile, Perú, Zambia y Zaire- proveen la mayoría del saldo exportable mundial de cobre. Malasia, Bolivia y Tailandia controlan un $70 \%$ de todo el estaño que se comercia internacionalmente. Cuba y Nueva Caledonia tienen bastante más de la mitad de las reservas mundiales probadas de níquel. Las principales reservas conocidas de cobalto están en Zaire, Cuba, Nueva Caledonia y partes de Asia. México, Perú y Australia controlan el $60 \%$ de la disponibilidad exportable de plomo. Finalmente, Jamaica, Surinam, Guyana y Guinea proveen alrededor de un $60 \%$ de la producción mundial de bauxita. ${ }^{7}$

Esta situación en que algunos pocos países del Tercer Mundo controlan la mayoría de las disponibilidades mundiales exportables plantea nuevas alternativas de acción para los países pobres que se han inspirado en el modelo OPEP para negociar sus recursos con los países ricos. La existencia de una situación que hemos denominado de "dependencia estratégica" por parte de las naciones industrializadas abre nuevas y mejores perspectivas para las naciones proletarias. Sin embargo, estos problemas son bastante complejos y merecen un análisis cuidadoso para así evitar caer en simplismos o en comparaciones demasiado fáciles. Por ejemplo, debemos dejar bien en claro que el petróleo tiene una importancia estratégica mucho mayor que cualquiera de los recursos claves a que habremos de referirnos. Desde este ángulo podríamos clasificar a las materias primas en tres grupos principales en orden decreciente de importancia: 1) El petróleo, 2) Todas las materias primas "claves" exceptuando el petróleo, y 3) El resto de las materias primas.

Lo que importa recalcar por ahora es que la concentración de grandes fuentes de abastecimiento en contadas regiones y en pocas manos ha dado lugar a un importante accionar por parte de los países ricos en búsqueda de nuevas reservas o de abastecimiento "seguro". La creciente importancia de estos recursos a su vez ha dado origen a su nacionalización, por parte de los países en desarrollo, con el fin de lograr el total control económico y político de lo que, en la mayoría de los casos, constituye la única fuente significativa de ingreso de divisas. De este modo, los recursos minerales plantean, en este período "post-boicot petrolero", una serie de problemas internacionales que contribuyen a la inestabilidad del actual orden político y económico internacional.

"Ibid., p. 6. Pierre Jaléc, La Course aux matières premières en "Le Monde Diplomatique", No 238, Janvier 1974, p. 12. 
El petróleo: arma revolucionaria de un grupo de paises en desarrollo

El estudio inicial publicado por el Club de Roma acerca de los límites del crecimiento fue el que apuntó por primera vez hacia el problema de que un mundo finito no posee acceso a recursos infinitos e inagotables ${ }^{8}$. Sin embargo, no fue hasta octubre de 1973 que los habitantes del mundo industrializado tomaron conciencia clara del asunto. Las restricciones artificiales a la oferta de petróleo -la principal fuente de energía mundial-y las considerables alzas de precio del hidrocarburo dejaron de ser una mera abstracción para transformarse en una experiencia concreta.

Pensando especialmente en las posibilidades del desarrollo de la energía nuclear, la mayoría de los expertos opinaba que las reservas mundiales de energía eran ilimitadas y totalmente seguras. En efecto, nadie atribuía importancia a la posibilidad de que fuerzas políticas pudieran eventualmente llegar a restringir la disponibilidad de materias primas tales como el petróleo.

No obstante, el 17 de octubre de 1973 Kuwait decretaba un boicot petrolero contra los Estados Unidos y Holanda, boicot al que inmediatamente se sumaría la Organización de los Países Arabes Exportadores de Petróleo (OPAEP).

El viejo orden monetario-financiero de la postguerra, caracterizado por el sistema de Bretton Woods, venía resquebrajándose desde hacía ya mucho tiempo y convirtiéndose en un "nuevo desorden bajo los cielos" al decir de Chou En-lai. Los paises en desarrollo, si bien participaban marginalmente de la expansión de las economías centrales, continuaban siendo testigos frustrados de su atraso cada vez mayor con respecto a aquellas economías, y de la acumulación de necesidades vitales que no lograban satisfacer o siquiera aliviar.

Sobre este trasfondo se precipita el boicot petrolero como una dramática manifestación de la crisis de las relaciones económicas internacionales.

En un comienzo, el embargo petrolero había surgido como una reacción frente al continuo apoyo norteamericano a Israel durante la guerra del Yom Kippur. En seguida, el embargo fue seguido por una drástica reducción de la producción del hidrocarburo de un $28 \%$, ante la cual el mundo occidental fue incapaz de responder. Los árabes habían descubierto en el embargo petrolero un nuevo instrumento de ataque que parecía bastante más efectivo que las modernas armas militares.

"Donclla H. Meadows et al., "The limits to growth" (Earth Island Limited, London, 1972). 


\section{ESTUDIOS INTERNACIONALES}

En una perspectiva a más largo plazo, la meta final de los países miembros de la OPEP ${ }^{9}$ parecía ser el establecimiento de un nuevo orden mundial. De ahí que el canciller argelino Abdelaziz Bouteflika declarase, en una reunión especial de ministros de la OPEP, que:

Los países productores de petróleo procuran desempeñar un papel cada vez más importante dentro del Tercer Mundo, y están conscientes de su considerable responsabilidad en la creación de un nuevo orden económico y la protección de los intereses de los países del Tercer Mundo que no producen petróleo. ${ }^{10}$

Según Bouteflika, el nuevo orden mundial tiene como objetivo principal el poner fin a "la explotación e intimidación del Tercer Mundo por los países industrializados no comunistas"11. Asimismo, el presidente venezolano Carlos Andrés Pérez, en una entrevista concedida al semanario parisiense "L'Express", declaró, refiriéndose a la OPEP, que: "Nosotros vamos a cambiar el mundo". ${ }^{12}$

La OPEP se ha transformado entonces en una potencia revolucionaria en el sentido que ha alterado el orden internacional "legítimo" que pretendía establecer el secretario del Estado norteamericano Henry Kissinger.

Esta nueva situación revolucionaria motivó declaraciones por parte del presidente de los EE. UU. Gerald Ford en el sentido de que las crecientes alzas del petróleo envolvían no sólo el riesgo de una "depresión mundial", sino que, además, podían producir "un quiebre del orden y de la seguridad mundiales". El "Washington Post" reconocía por su parte que la OPEP "no sólo utiliza el petróleo como arma política, sino también como arma revolucionaria..., revolucionaria en el sentido de que lo está utilizando en forma deliberada, para provocar cambios drásticos en la estructura de poder mundial". ${ }^{13}$

${ }^{\circ}$ Los miembros de la OPEP son: Arabia Saudita, Irán, Venczuela, Nigeria, Libia, Kuwait, Iraq, Emiratos Arabes Unidos, Argelia, Indonesia, Katar y Ecuador. Gabón es un miembro asociado. Los Emiratos Arabes Unidos son una fedcración constituida por: Abu Dhabi, Dubai, Sarjah, Ahjman, Umm al Quwain, Ras al Khaimah y Fujairah.

${ }^{10}$ Abdelaziz Bouteflika citado en cable de Associated Press en "La Tercera", 25 de cnero de 1975 , p. 15.

${ }^{11}$ Loc. cit.

${ }^{13}$ Carlos Andrés Pérez, citado en cable de Associated Press en "El Mercurio". 9 de marzo de 1975 , p. 40.

${ }^{15}$ Citado por Gustavo Lagos, El Petróleo: la nueva revolución de Octubre, "Mensaje", No 234, noviembre de 1974, p. 534. 
DEPENDENGIA ESTRATÉGICA Y DEPENDENCIA NO-ESTRATÉGICA

\section{Hacia una definición de los conceptos}

Lo que la crisis del petróleo ha venido a demostrar es que el rol de algunas materias primas es de vital importancia para la seguridad nacional de los diversos países. No obstante, no se trata simplemente de que un país tenga o no tenga materias primas, sino que más bien interesa el "grado de dependencia" que el país tenga respecto de aquellas materias primas "claves" para el funcionamiento de su economía o para el mantenimiento y desarrollo de su industria bélica.

De allí que podríamos introducir el concepto "Dependencia Estratégica" para identificar la situación en que una nación depende en un alto grado de la importación de materias primas claves para su economía, especialmente en lo que respecta a industrias estratégicas asociadas con la seguridad nacional del país. Por lo tanto, una alta dependencia respecto de una materia prima tan importante como el petróleo significaría un alto grado de "dependencia estratégica".

Sin embargo, no podríamos limitarnos a considerar sólo una o dos materias primas, sino que sería conveniente tomar un número " $\mathrm{X}$ " de recursos y asignarles mayor o menor prioridad dependiendo de la importancia que le otorguen los expertos. Para estos propósitos hemos procedido a utilizar el libro "Yacimientos minerales de rendimiento económico" de Alan M. Bateman quien sostiene que existe una serie de "minerales importantes" que son vitales para las industrias básicas de los países desarrollados y, más aún, esenciales en la guerra moderna mecanizada. Estos minerales serían los siguientes: petróleo, hierro, metales no-ferrosos, metales ferrosos, mercurio, antimonio, azufre, asbesto, grafito, magnesita, mica, cuarzo, fluorita, platino, berilio, tantalita, uranio y diamantes industriales. ${ }^{14}$

Utilizando el criterio de Bateman para identificar minerales efectivamente estratégicos, se podría entonces comparar las cifras de distribución de las reservas probadas de las diferentes materias primas para así determinar con exactitud lo que hemos denominado grado de "dependencia estratégica" de los países. Parte de este trabajo ya fue realizado por el propio Bateman quien confeccionó un cuadro en que ubica horizontalmente las principales reservas en diversos países $y$, verticalmente, las reservas de estos mismos países en los

14Alan M. Bateman, "Yacimientos minerales de rendimiento cconómico" (Ed. Omega, Barcelona, 1968), 3a cd., pp. 401-406. 


\section{Cuadro 1}

DISTRUBUCióN DE MINERALES IMPORTANTES Y CATEgoría DE LOS PRINCIPALES PAISES

(A, adecuada o con excedente; $\mathrm{D}$, déficit importante; $\mathrm{O}$, ausente)

\begin{tabular}{|c|c|c|c|c|c|c|c|c|c|c|c|c|c|c|c|c|c|c|c|}
\hline $\begin{array}{l}\text { Minerales } \\
\text { importantes }\end{array}$ & $\begin{array}{l}\text { S } \\
\text { s. } \\
\text { si }\end{array}$ & 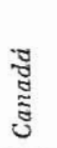 & 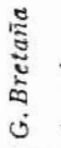 & & 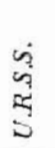 & 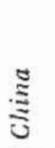 & $\frac{\widetilde{\pi}}{\mathbb{T}}$ & $\stackrel{\Xi}{\Xi}$ & $\stackrel{\overrightarrow{0}}{\stackrel{5}{\Xi}}$ & $\frac{\widetilde{3}}{\widetilde{3}}$ & 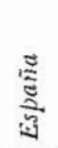 & 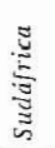 & & $\overrightarrow{\frac{\overrightarrow{3}}{2}}$ & 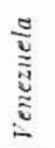 & 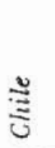 & R & 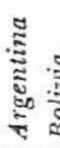 & \\
\hline $\mathrm{H}$ & A & A & D & A & $A$ & A & $D$ & D & D & $D$ & A & A & D & $A$ & A & 7. & $\mathrm{O}$ & D & O \\
\hline & $A$ & A & O & o & D & $\mathrm{O}$ & D & o & D & () & A & $A$ & A & $\mathrm{O}$ & $\mathrm{O}$ & 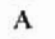 & A & 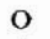 & 0 \\
\hline Plon & I & A & D & $\mathrm{O}$ & A & D & 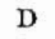 & $\mathrm{D}$ & O & $A$ & A & D & A & $\mathrm{O}$ & $\mathrm{O}$ & o & A & A & A \\
\hline $\mathrm{Zi}$ & I & A & D & 0 & A & D & 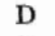 & A & D & $A$ & x & 1 & A & $\mathrm{O}$ & $\mathrm{O}$ & $\mathrm{O}$ & A & 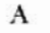 & A \\
\hline & . & O & D & o & $\mathrm{O}$ & A. & 0 & $\mathrm{O}$ & O & 0 & o & D & D & $\mathrm{O}$ & $\mathrm{O}$ & 0 & 0 & 0 & A \\
\hline & A & $O$ & o & A & $\mathrm{D}$ & $\mathrm{O}$ & O & A & $\mathrm{O}$ & () & O & 0 & $\mathrm{O}$ & A & $\mathrm{O}$ & O & O & $\mathrm{O}$ & o \\
\hline & D & O & o & O & $\mathrm{A}$ & $\mathrm{O}$ & O & D & D & c. & J & . & $\mathbf{A}$ & A & $\mathrm{O}$ & A & O & $\mathrm{O}$ & o \\
\hline & D & $O$ & o & O & $\Lambda$ & $\mathbf{O}$ & $\mathrm{O}$ & 0 & D & 0 & $\mathrm{O}$ & A & 0 & 0 & $\mathrm{O}$ & O & $\mathrm{O}$ & $\mathrm{O}$ & 0 \\
\hline & 0 & A & O & $\mathrm{O}$ & A & $\mathrm{O}$ & $\mathrm{O}$ & O & $\mathrm{O}$ & 0 & $\mathrm{O}$ & D & 0 & O & D & O & 0 & O & 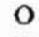 \\
\hline & A & D & O & $\mathrm{O}$ & D & $\mathrm{O}$ & D & $\mathrm{O}$ & $\mathrm{O}$ & O & $\mathrm{O}$ & 0 & A & $\mathrm{O}$ & $\mathrm{O}$ & A & D & D & 0 \\
\hline & I & D & O & 0 & $\mathrm{D}$ & A & ? & 0 & D & O & D & D & A & $A$ & 0 & J & $\mathrm{O}$ & A & 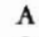 \\
\hline & I & O & O & O & D & 0 & 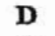 & O & 0 & () & 0 & A & D & O & O & $\mathrm{O}$ & A & O & 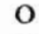 \\
\hline Cob & D & $\mathbf{A}$ & D & 0 & D & O & 0 & 0 & O & O & $\mathrm{O}$ & A & O & $\mathrm{O}$ & $\mathrm{O}$ & 0 & $\mathrm{O}$ & $\mathrm{O}$ & $\mathrm{O}$ \\
\hline Merc & D & A & O & $\mathrm{O}$ & D & D & O & A & $\mathrm{D}$ & $O$ & A & 0 & A & O & $\mathrm{O}$ & 0 & D & $\mathrm{O}$ & D \\
\hline Antir & D & $\mathrm{D}$ & D & $\mathrm{O}$ & D & A & 0 & D & $\mathrm{D}$ & 0 & $\mathrm{O}$ & $\mathrm{O}$ & A & $\mathrm{O}$ & 0 & 0 & D & O & A \\
\hline Or & A & $\Lambda$ & o & A & $\mathrm{O}$ & $\mathrm{O}$ & O & D & D & I) & $\mathrm{O}$ & A & D & $\mathrm{O}$ & D & D & D & D & D \\
\hline & D & A & O & $\mathrm{O}$ & A & O & $\mathbf{O}$ & $\mathrm{O}$ & O & 0 & O & A & 0 & O & O & O & $\mathrm{O}$ & $\mathrm{O}$ & O \\
\hline Tá & $\mathrm{O}$ & $\mathrm{O}$ & O & $\mathrm{O}$ & $?$ & $\mathrm{O}$ & $\mathrm{O}$ & 0 & $\mathrm{O}$ & 0 & $\mathrm{O}$ & A & o & A & $\mathrm{O}$ & $\mathrm{O}$ & $\mathrm{O}$ & o & $\mathrm{O}$ \\
\hline & A & A & A & A & A & A & A & o & $\mathrm{D}$ & $\Lambda$ & O & A & O & D & $\mathrm{O}$ & A & A & A & D \\
\hline & A & A & $\mathrm{O}$ & O & A & $\mathrm{O}$ & D & O & D & I) & $\mathrm{O}$ & O & A & O & A & D & $\Lambda$ & D & $\mathrm{O}$ \\
\hline Azufre & A & D & $\mathrm{O}$ & O & A & 0 & I & A & A & O & A & D & D & 0 & $\mathrm{O}$ & D & A & 0 & o \\
\hline P & A & $\mathrm{O}$ & o & A & A & $\mathrm{O}$ & A & $\mathrm{O}$ & $\mathrm{O}$ & A & A & $\mathrm{O}$ & $\mathrm{O}$ & O & $\mathrm{O}$ & D & O & $\mathrm{O}$ & $\mathrm{O}$ \\
\hline Fosfa & A & A & O & O & D & $\mathrm{O}$ & I & $\mathrm{O}$ & O & I) & O & D & $\mathrm{O}$ & O & O & O & O & 0 & O \\
\hline & A & D & A & D & A & 0 & A & D & D & 0 & A & D & A & O & $\mathrm{O}$ & $\mathrm{O}$ & D & D & O \\
\hline & I & A & $\mathrm{O}$ & 0 & $\mathrm{O}$ & 0 & O & $\mathrm{O}$ & O & 0 & $\mathrm{O}$ & A & O & 0 & D & $\mathrm{O}$ & $\mathrm{O}$ & D & O \\
\hline G & I & A & $\mathrm{O}$ & O & A & $\mathrm{O}$ & A & D & A & 0 & 0 & O & A & $\mathrm{O}$ & 0 & $\mathrm{O}$ & $\mathrm{O}$ & $\mathrm{O}$ & O \\
\hline ? & A & $\mathrm{O}$ & $\mathrm{O}$ & $\mathrm{O}$ & $\mathrm{D}$ & A & D & $\mathrm{O}$ & A & 0 & $\mathrm{O}$ & D & 0 & O & $\mathrm{O}$ & $\mathrm{O}$ & $\mathrm{O}$ & $\mathrm{O}$ & $\mathrm{O}$ \\
\hline & $\mathrm{D}$ & D & O & O & $\mathrm{O}$ & D & O & $\mathrm{O}$ & D & 0 & O & D & A & $\mathrm{O}$ & $\mathrm{O}$ & $\mathrm{O}$ & $\mathrm{O}$ & $\mathrm{O}$ & O \\
\hline & $\mathrm{O}$ & O & O & O & O & $\mathrm{O}$ & $\mathrm{O}$ & $\mathrm{O}$ & O & 0 & 0 & A & 0 & A & D & 0 & $\mathrm{O}$ & $\mathrm{O}$ & O \\
\hline Cuarzo & I & $\mathrm{O}$ & 0 & $\mathrm{O}$ & O & $\mathrm{O}$ & $\mathrm{O}$ & $\mathrm{O}$ & O & 0 & $\mathrm{O}$ & $\mathrm{O}$ & 0 & A & $\mathrm{O}$ & $\mathrm{O}$ & O & 0 & O \\
\hline en & 1 & 14 & 2 & 4 & 16 & 6 & 4 & 4 & 3 & 4 & 8 & 13 & 12 & 8 & 2 & 5 & 7 & 4 & \\
\hline & 14 & 6 & 6 & 1 & 10 & 3 & 10 & 6 & 12 & 3 & 2 & 9 & 5 & 2 & 3 & 4 & 5 & 3 & \\
\hline Ausentc & 4 & 10 & 22 & 25 & 3 & 21 & 16 & 20 & 15 & 23 & 20 & 8 & 13 & 20 & 25 & 21 & 22 & 22 & 0 \\
\hline
\end{tabular}


mincrales claves. Como podemos ver en el Cuadro l, "A" designa una reserva adecuada, "D" designa una importante deficiencia que tiene que ser compensada con importaciones y "O" designa ausencia o cantidades sin importancia. ${ }^{15}$

El cuadro citado nos da una información clara de los excedentes y carencias de recursos minerales importantes.

Respecto de EE. UU. observamos lo siguiente: carencia total de cuatro minerales claves, déficit en catorce y un excedente real en doce, además de ser el principal productor mundial de ocho minerales esenciales.

Por otra parte, podemos ver que la URSS se ve muy bien abastecida, con pocos déficits de importancia. Es la principal productora mundial de manganeso, y la segunda en mineral de hierro, cromo, platino y asbesto. Posee además abundantes reservas de petróleo y de la mayor parte de los metales no-ferrosos.

Francia, Alemania, Italia y Japón aparecen notablemente defici. tarias en la mayoría de los minerales de capital importancia.

Cabe destacar que el cuadro de Bateman fue confeccionado hace ya más de dos décadas y aclolece de varios errores. Por ejemplo, respecto de la República Popular China se indica un déficit en lo que a petróleo se refiere, en consideración que actualmente China no sólo se autoabastece del preciado hidrocarburo sino que además lo exporta a países tales como Japón, Vietnam del Norte, Corea del Norte y Tailandia ${ }^{16}$. Sin embargo, es interesante observar que, en términos generales, las tendencias que se vislumbraban hace casi treinta años atrás se han mantenido hasta ahora. Consecuentemente, la aguda "dependencia estratégica" que ya se observaba en aquel entonces en países como Japón y Alemania se ha visto clramáticamente descubierta con ocasión de la crisis del petróleo.

Otro hecho notable que pone de manifiesto el cuadro a que nos hemos referido es que la "dependencia estratégica" no sólo es característica de los "países industrializados" sino que también afecta a los países en vías de desarrollo creando problemas similares en lo que respecta a seguridad nacional y, además, provocando obstáculos adicionales al desarrollo. No obstante, aquí el impacto de la dependencia estratégica es considerablemente menor debido justamente al atraso industrial de los países pobres. En todo caso, sí afectará significativamente a países en desarrollo con mayor grado de desarrollo industrial y con industrias bélicas autónomas tales como Argentina y Brasil.

${ }^{25}$ Ibid., p. 402.

10.Ver Heraldo Muñoz, "La República Popular China y la Crisis del Petrólco", documento de trabajo, Depto. Estudios Internacionales, Universidad de Chile. 
Por otro lado, el cuadro indica que muchos países en desarrollo poseen grandes recursos en minerales de vital importancia lo que resulta especialmente relevante en una perspectiva política y a la luz del boicot petrolero de la OPAEP.

Debido a que los datos proporcionados en el trabajo de Bateman resultan bastante añejos, a la vez que sus criterios para designar algunos minerales como claves parecen poco relevantes a la situación de la ciencia y la tecnología en la era atómica, hemos procedido a utilizar un informe especial realizado bajo la supervisión del "Council on International Economic Policy" y el "National Security Council" de EE. UU. en que se identifican 19 materias primas críticas por la seguridad nacional de la superpotencia del norte ${ }^{17}$. De esta manera tomamos en cuenta el carácter cambiante de la tecnología que puede elevar o reducir la importancia de cualquier recurso.

Según el informe -en que participaron agencias norteamericanas tales como el Departamento de Estado, la Agencia Central de Inteligencia (CIA), el Departamento del Tesoro, el Departamento de Defensa, el Departamento del Interior, el Departamento de Comercio y otros- los minerales denominados críticos, exceptuando el petróleo, serían los siguientes: Aluminio-Bauxita, Cromo, minerales del grupo Platino, Hierro, Níquel, Caucho, Manganeso, Zinc, Estaño, Titanio, Cobalto, Mercurio, Tungsteno, Plomo, Columbio, Vanadio, Fluorita, Cobre y Fosfatos. ${ }^{18}$

Como podemos observar, prácticamente todos los minerales denominados "críticos" por el informe citado aparecen en la lista de minerales importantes de Bateman, por lo que podemos formarnos una "idea aproximada" de la dependencia estratégica de los diversos países -en términos relevantes al momento actual- seleccionando los datos acerca de los 19 minerales mencionados anteriormente. Un punto que es necesario precisar es la importancia relativa de cada uno de estos 19 minerales "críticos". Aquellos más estrechamente ligados con la producción de armamentos sofisticados deberán ser ponderados al doble reflejando así su mayor valor estratégico ${ }^{19}$. En este sentido, deberíamos agregar a la lista anterior metales como el berilio, el tario, el circonio, el litio y el uranio que son indispensables

${ }^{17}$ "Critical Imported Materials", Special Report, Council on International Economic Policy (U.S. Government Printing Office, Washington, D.C., December 1974).

${ }^{18}$ Ibid., p. 24.

${ }^{10}$ En 1936, Ferdinand Friedensburg, un estadístico alcmán, clasificó la importancia de un número de mincralcs básicos para la producción industrial con fincs militares y les asignó los siguientes valores: carbón, 40; petróleo, 20; accro, 15; cobre, plomo, manganeso y azufre, 4 cada uno; y zinc, aluminio y níquel, 2, también cada uno. Hoy en dáa, casi 40 años más tarde, la porción del petrólco tendria que ser considerablemente mayor. 
para la edificación de reactores atómicos y para la industria atómica en general. El caso del uranio es particularmente interesante, pues se estima que hacia el año 2.000, debido al futuro aumento en el consumo de energía nuclear, estará escaseando y, por tanto, agudizando la dependencia estratégica de aquellos países carentes del recurso $^{20}$. Esto significa que una nación que intenta disminuir su dependencia estratégica sustituyendo - por ejemplo- el consumo del petróleo por el uso de energía nuclear, puede llegar a agudizar aún más su dependencia si también sufre un déficit de uranio.

Se estima que la demanda de uranio superará a la oferta hacia mediados de la década de 1980. En el siguiente cuadro se puede observar las necesidades crecientes de uranio en las próximas décadas:

Cuadro 2

NECESIDADES MUNDIALES DE URANIO ACUMULATIVAS"

\begin{tabular}{cc}
\hline Año & $\begin{array}{c}\text { Necesidades acumulativas } \\
\text { (103 toneladas) }\end{array}$ \\
\hline 1973 & 17 \\
1975 & 60 \\
1980 & 270 \\
1985 & $500-700$ \\
1990 & $700-1.400$ \\
1995 & $1.000-2.000$ \\
2000 & $3.500-7.700$
\end{tabular}

"Estimaciones que se basan en suposiciones acerca de las caracteristicas operacionales de futuros reactores atómicos.

FUENTE: "The Nuclear Age", SIPRI, op. cit., p. 59.

Ahora bien, al introducir el concepto de "dependencia estratégica" hemos planteado la existencia de una "dependencia no-estratégica", situación que a su vez requiere una definición apropiada.

Por "dependencia no-estratégica" entendemos la situación en que una nación depende en gran medida del exterior para su abastecimiento de materias primas "no-claves" pero que además implica una "subordinación general" del país respecto de un centro hegemónico externo. En otras palabras, la "dependencia no-estratégica" es de ex-

20"The Nuclear Age", SIPRI, Almaqvist \& Wiksell International, Stockholm, Sweden, 1974. Ver, además, “La energía nuclear como respuesta a la crisis energética", Comisión de Energía Nuclear, Santiago de Chile, abril de 1974. 
traordinaria importancia para el bienestar general del país, especialmente a largo plazo, pero no implica los "peligros inmediatos" a la seguridad nacional de una dependencia estratégica.

\section{Dependencia estratégica: ¿La dependencia al revés?}

En un mayor o menor grado, las economías de los países en desarrollo tienden a conformar un tipo de economía dependiente denominada "economía satélite" atada a un centro hegemónico o "economía dominante". Esta relación de dependencia se caracteriza, en el área cconómica, en un ostensible deterioro de los términos de intercambio; en una baja de la posición relativa del país dependiente en el campo del comercio mundial; en la necesidad de inversiones provenientes del extranjero; en la ausencia de una sub-cultura innovadora en lo que a ciencia y tecnología se refiere -y por tanto en la necesidad de importar tecnologia- y, finalmente, en un alto grado de penetración de las economías locales por parte de las empresas multinacionales.

Sin embargo, la situación de dependencia en que se encuentran los países en desarrollo no se limita exclusivamente al sector económico, sino que se extiende a los campos político, científico-tecnológico, militar y cultural.

Por otra parte, es importante destacar que el concepto "dependencia" debe ser visto desde una dimensión "histórico-estructural" que supere la distinción analítica entre factores externos e internos, que tiende a ocultar la unidad estructural que existe entre ambos ${ }^{21}$. El concepto de dependencia supera entonces la dicotomía "externo-interno", "mundo desarrollado y mundo subdesarrollado" incluyéndolos en una estructura unitaria: el sistema capitalista internacional. La aparente oposición entre desarrollo y subdesarrollo no representa más que dos aspectos recíprocos y complementarios de un mismo proceso, es decir, el desarrollo del capitalismo a nivel mundial, que da origen al imperialismo y a la dependencia.

Es justamente debido a que la situación de dependencia en América Latina es consecuencia de un "proceso histórico" que la define, que no se puede plantear linealmente un análisis de una dependen-

${ }^{21}$ Ver Fernando Henrique Cardoso y Enzo Faletto, "Dependencia y desarro. Ilo en Amćrica Latina" (Ed. Siglo xxı, México, D. F., 1969) : Aníbal Quijano, "Dependencia, cambio social y urbanización en Latinoamérica" en "América Latina: Ensayos e interprctación sociológico-política", F. H. Cardoso y F. Weffort, eds. (Editorial Univcrsitaria, S. A., Santiago, 1970); Orlando Caputo y Roberto Pizarro, "Imperialismo, Dependencias y Relaciones Económicas Internacionales", Cuadernos de Estudios Socio-Económicos, CESO, Universidad de Chile, 1972. 
cia al revés cuando nos referimos a la "dependencia estratégica" de los países industrializados. Si lo hiciésemos incurriríamos en una falsificación teórica y práctica, ya que estaríamos distorsionando e] contenido del proceso histórico de expansión e internalización del capital, además de los elementos teóricos que de él se desprenden.

En consecuencia, el concepto "dependencia estratégica" debe ser considerado solamente como una situación de debilidad de la estructura en que se apoya el sistema capitalista. Representa un momento crítico para el orden consagrado en la actual división internacional del trabajo. Sin embargo, la existencia de una "dependencia estratégica" en los países ricos tampoco significa que la presente división internacional del trabajo está en vías de ser modificada, sino que más bien ofrece una oportunidad a disposición de las naciones en desarrollo para desarrollar una estratégica común destinada a explotar la situación de dependencia señalada.

En resumen, la "dependencia estratégica" de los países industrializados es una situación que podríamos denominar de "dependencia sectorial" que se contrapone con la "dependencia generalizada" de los países pobres, siendo ambas aspectos complementarios de una misma realidad. Si pudiésemos ilustrar ambas situaciones por medio de fórmulas tendríamos que:

Países ricos $(-\mathrm{d}$. no-estratćgica $)+\mathrm{d}$. estratégica $=$ dependencia sectorial

Paises pobres $(+\mathrm{d}$. no-estratégica $)+\mathrm{d}$. estratégica $=$ dependencia generalizada

Es decir, la formulación de la "dependencia estratégica" no nos permite de ningún modo plantear una situación de dependencia del polo desarrollado de la humaniclad que se pone de rodillas frente a los "históricamente subdesarrollados" poseedores de materias primas estratégicas. Esto sería absurdo. A lo sumo podemos decir que los países desarrollados experimentan una situación de "dependencia sectorial" y momentánea que se contrapone con la "dependencia generalizada" tradicional de los países subdesarrollados. La dependencia estratégica, además, plantea un desafío al hegemonismo que caracteriza las relaciones internacionales contemporáneas, y puede llegar a servir como un instrumento a disposición de los países en desarrollo para lograr una modificación radical del orden político y económico internacional actual. 


\section{Dependencia estratégica y estratificación internacional}

La crisis petrolera no sólo constituye un primer antecedente de lo que hemos decidido llamar "dependencia estratégica" sino que además ha alterado fundamentalmente la estructura de lo que el profesor Gustavo Lagos ha denominado el "sistema estratificado internacional". 22

Según el profesor Lagos, las posiciones que ocupa una nación dentro del sistema internacional pueden ser jerarquizadas básicamente en términos de: 1) Estatura y desarrollo económicos; 2) Poder militar, y 3) Prestigio. Cada nación ocupa varias posiciones en estos tres aspectos; así se puede hablar de "status económico" de un país, de su "status de poder" y de su "status de prestigio". El "status real" total de una nación está determinado por el complejo resultante de su posición en las tres jerarquías señaladas. ${ }^{23}$

Los elementos que componen el "status económico" de“una nación son los siguientes: a) Grado de desarrollo económico y tecnológico, b) Potencialidad económica medida por la cuantía del P.N.B., y c) Grado de desarrollo social apreciado por el nivel de vida promedio.

Los componentes del "status de poder" son: a) La madurez tecnológica, es decir, la capacidad de una nación para aplicar efectivamente, de manera normal, regular y sistemática, la amplia gama de la moderna tecnología existente a la explotación del conjunto de sus recursos; b) La relación entre PNB y el presupuesto de defensa de la nación; c) La relación entre la cuantia del presupuesto de defensa y el financiamiento necesario para participar en la carrera tecnológica con aplicaciones militares.

Por último, el "status de prestigio" de una nación está determinado por dos factores: a) Síntesis del status de la nación en las pautas de poder militar y del económico, y b) Grado de concordancia entre la conducta internacional de la nación y las orientaciones de valor del sistema internacional.

Como podemos comprobar, ninguno de los países miembros de la OPEP ocupa una posición de importancia en cualquiera de los tres status que conforman el "status real". Sin embargo, potencias mundiales tales como los países de Europa Occidental y Japón se vieron obligados, debido al embargo petrolero, a plegarse a las tesis árabes en contra de Israel, tomando así conciencia de la disminución de su

${ }^{22}$ Gustavo Lagos, "International Stratification and Underdeveloped Countries", University of North Carolina Press, 1963.

sabid., pp. 3-30. 
status internacional y del repentino mejoramiento del "status real" de los países afiliados a la OPEP.

De lo anterior se desprende que la teoría de la estratificación internacional necesita ser reevaluada a la luz de la crisis petrolera, procurando introducir nuevos elementos que nos ayuden a comprender la nueva situación internacional emergida a raíz de los acontecimientos de octubre de 1973. En este sentido se podría incluir como un nuevo componente del "status de poder" al grado de "dependencia estratégica" de un país, lo que implicaría que a mayor grado de "dependencia estratégica" de una nación menor sería la posición del país en el "status de poder" y, por ende, en el "status real" total.

LA DEPENDENCIA ESTRATÉGICA EN LOS PAÍSES DESARROLLAdOS

\section{Los casos de EE. UU., Japón, Francia y Alemania Federal}

Como hemos dicho anteriormente cada Estado depende en cierta me. dida de recursos minerales importados. No obstante, lo que importa es determinar el grado de dependencia estratégica de que sufren los diversos países, especialmente aquellas naciones altamente industrializadas. En esta perspectiva hemos procedido a seleccionar cuatro casos que parecen especialmente importantes, no sólo en el sentido en que puedan contribuir a apoyar nuestra hipótesis principal, sino que, además, por consideraciones prácticas que podrían influir en la orientación de la estrategia de los carteles productores de materias primas.

1) Estados Unidos: En términos generales, la dependencia estratégica de los EE. UU. es más bien modesta si la comparamos con la de otras potencias industrializadas tales como Japón o la CEE. EE. UU. importa entre un 15 y un $20 \%$ de los minerales críticos que consume. ${ }^{24}$

Casi $2 / 3$ de sus importaciones de materias primas claves los obtiene de Canadá, Australia y Sudáfrica, lo que significa que el problema de asegurar el abastecimiento de minerales claves no está centrado en las relaciones EE. UU.-Tercer Mundo. Sin embargo, EE. UU. depende de los países en desarrollo para su abastecimiento de minerales esenciales tales como la bauxita, el manganeso, el esta-

¿4"Critical Imported Materials", Op. cit., p. 4. 


\section{ESTUDIOS INTERNACIONALES}

ño y el caucho natural. Por otro lado, EE. UU. depende exclusivamente de la URSS para la obtención de los metales del grupo platino y del cromo. El Cuadro 3 que se exhibe en la presente página nos da una idea general de la dependencia estratégica de EE. UU. que va desde el autoabastecimiento total en lo que respecta a fos. fatos, hasta una completa dependencia en lo que a estaño y cromo se refiere.

\section{Cundro 3}

DEPENDFNGIA ESTRATERICA DF. EE. UU,

(Importaciones, 1973)

1) = Producción doméstica*

2 ) $=$ Importaciones de países desarrollados (incluidos los socialistas)*

$3)=$ Importación de países del Tercer Mundo*

\begin{tabular}{|c|c|c|c|c|c|c|c|c|}
\hline Fosfatos & 1) & $100 \%$ & - & & & & & \\
\hline Colsre & 1) & $85 \%$ & - & 2) & $7 \%$ & - & 3) & $8 \%$ \\
\hline Vanadio & 1) & $73 \%$ & - & 2) & $18 \%$ & - & 3) & $9 \%$ \\
\hline Hierro & 1) & $72 \%$ & - & 2) & $15 \%$ & - & 3) & $13 \%$ \\
\hline Titanio & 1) & $67 \%$ & - & 2) & $33 \%$ & - & & \\
\hline Plomo & 1) & $64 \%$ & - & 2) & $18 \%$ & - & 3) & $18 \%$ \\
\hline Tungsteno & 1) & $56 \%$ & - & 2) & $29 \%$ & - & 3) & $15 \%$ \\
\hline Tinc & 1) & $49 \%$ & - & 2) & $37 \%$ & - & 3) & $14 \%$ \\
\hline Niquel & 1) & $10 \%$ & - & 2) & $90 \%$ & - & & \\
\hline Colsalto & I) & $5 \%$ & - & 2) & $50 \%$ & - & 3) & $45 \%$ \\
\hline Manganeso & 1) & $5 \%$ & - & 2) & $20 \%$ & - & 3) & $75 \%$ \\
\hline Platino & 1) & $1 \%$ & - & 2) & $96 \%$ & - & 3) & $3 \%$ \\
\hline Cromo & & & & 2) & $62 \%$ & - & 3) & $38 \%$ \\
\hline Estaño & & & & 2) & $5 \%$ & - & 3) & $95 \%$ \\
\hline Bauxita & I) & $10 \%$ & - & 2) & $47 \%$ & - & 3) & $43 \%$ \\
\hline
\end{tabular}

* Como porcentajc del consumo.

Como veremos más adelante, los problemas que deben enfrentar los países desarrollados en lo que respecta a las diversas materias primas son básicamente dos: 1) Problemas de disponibilidad que pueden surgir en razón de embargos u otro tipo de interrupciones, y 2) Problemas de precio motivados por el accionar de los carteles de productores.

Según el informe del "Council on International Economic Policy" citado previamente, cualquiera restricción a la oferta provocada en maniobras de carteles destinadas a lograr mejores precios no impli- 
caría mayores peligros a la seguridad nacional de la nación, aunque sí traerían importantes efectos secundarios, especialmente si la restricción es prolongada.

Por el contrario, cualquier embargo "tipo OPAEP" ocasionaría graves problemas a la superpotencia norteamericana, más aún si se produce durante una situación de emergencia nacional. No obstante, desde fines de la Segunda Guerra Mundial, los EE. UU. han protegiclo su industria estratégica contra posibles interrupciones al abastecimiento de minerales claves por medio de la mantención de stocks de reservas superiores a sus necesidades auténticamente industriales. En todo caso, desde fines de la década del 60 los objetivos de los stocks estratégicos han sido disminuidos en varias ocasiones, reflejando la tendencia cambiante de la demanda y el cambio en las percepciones acerca de los períodos de tiempo que podían ser cubiertos en los stocks existentes.

Por otro lado, existen algunos autores que opinan que aun en el caso de un embargo de varios minerales claves, los EE. UU. se verían muy poco afectados debido a que cualquiera economía industrial moderna como la de EE. UU. se adapta en forma increíblemente rápida a la escasez de materias primas. El único problema sería un "shock inicial" derivado de la interrupción brusca del abastecimiento de la materia prima en particular, lográndose a la larga una adaptación adecuada a las nuevas condiciones. La economía no sufriría un colapso aunque sí disminuirían los standards de vida. ${ }^{25}$

En resumen, el grado de dependencia estratégica de EE. UU. es relativamente bajo, aunque no lo suficientemente bajo para evitar posibles boicots o interrupciones artificiales que de producirse le ocasionarian graves problemas. Conviene destacar que las proyecciones muestran que hacia 1985 los EE. UU. dependerán de importaciones para más de la mitad de sus abastecimientos de petróleo y gas natural, y que más de un $50 \%$ del abastecimiento de 9 de 19 de los minerales críticos provendrá del exterior. Finalmente, en 1970 las importaciones de combustibles energéticos y minerales costaron a EE. UU. 8 mil millones de dólares, estimándose que esta suma subirá a 31 mil millones de dólares hacia 1985, suponiendo precios constantes, suposición que, está demás decirlo, ya no se considera realista. ${ }^{26}$

2) Japón: Tanto EE. UU. como Japón deben importar minerales claves. Sin embargo, los grados de dependencia estratégica entre am. bos paises son radicalmente diferentes.

${ }^{25}$ Ver Charles L. Schultze, The economic content of national security policy, "Foreign Affairs", April 1973, pp. 525-526.

${ }^{20} L$ ester Brown, Op. cit., p. 5. 
En materia de energía, la dependencia de Japón de fuentes externas es solamente comparable a la de Italia. Sin embargo, sus competidores tienen un mayor grado de autoabastecimiento y una menor dependencia del petróleo como principal fuente de energía. El petróleo satisface alrededor de un 74,9\% de las necesidades primarias de energía del país asiático, del cual un $99,7 \%$ proviene del exterior. ${ }^{27}$

A diferencia de EE. UU., la dependencia japonesa se extiende a la mayoría de los minerales claves que determinan el mayor o menor grado de dependencia estratégica. Japón importa más del $90 \%$ de su abastecimiento de mineral de cromo, manganeso, níquel, estaño y cobre; casi un $100 \%$ de sus fosfatos, y más de un $75 \%$ de su plomo y varios otros metales esenciales. En el Cuadro 4 se observa la gran diferencia que existe entre la dependencia estratégica de Japón y la de EE. UU. ${ }^{28}$

Los principales proveedores en el caso de Japón difieren significativamente de los EE. UU. e incluso de los de Europa. Las principales fuentes de abastecimiento de Japón -como veremos en el Cuadro 5- son los países del Tercer Mundo, especialmente los de Asia Meridional y el Sudeste Asiático, además de Australia.

Es interesante destacar que Japón solía ser un país exportador de cobre. Sin embargo, debido a su alta tasa de crecimiento económico, el consumo del mineral ha aumentado extraordinariamente. En 1972 Japón estaba importando un $84 \%$ de su consumo total de cobre y sus principales proveedores eran Canadá (37,5\%), Filipinas $(32,9 \%)$, Australia $(7,5 \%)$ y, en forma creciente, varios paises de África y América Latina. ${ }^{29}$

Como podemos constatar, el grado de dependencia estratégica de Japón es extraordinariamente elevado y de acuerdo a algunas proyecciones es posible que en el futuro se agudice aún más.

Para aminorar los efectos negativos de su alto grado de dependencia estratégica, Japón ha implementado una serie de acciones internacionales a largo y mediano plazo tales como inversiones y préstamos a países subdesarrollados productores de materias primas. Los préstamos, por lo general, se otorgan a entidades privadas de los países para la compra en Japón de maquinaria destinada a expandir las capacidades de la industria. Los japoneses aceptan como pago parte de la producción resultante del proyecto. Este tipo de arreglos

27"Ver R. P. Sinha, Japan and the oil crisis, "The World Today", Chatham House, Vol. 30, No 8, August 1974, pp. 338-339.

${ }^{28}$ "Critical Imported Materials", Op. cit., pp. 42-43.

${ }^{2}$ Saburo Okita, Natural resource dependency and Jafranese foreign policy, en "Foreign Affairs", July 1974, p. 719. 


\section{CuADro 4}

DEPENDENCIA ESTRATÉGICA DE EE, UU. Y JAPÓN

(algunos mincrales, 1972)

\begin{tabular}{|c|c|c|c|c|}
\hline & \multicolumn{2}{|c|}{ EE. $U U$. } & \multicolumn{2}{|c|}{ Japón } \\
\hline & $\begin{array}{l}\text { Vol. de } \\
\text { importac. } \\
\text { (miles de } \\
\text { tons.) }\end{array}$ & $\begin{array}{l}\text { Inportac. } \\
\text { como \% de } \\
\text { consumo }\end{array}$ & $\begin{array}{c}\text { Vol. de } \\
\text { importac. } \\
\text { (miles de } \\
\text { tons.) }\end{array}$ & $\begin{array}{c}\text { Inporlac. } \\
\text { como \% de } \\
\text { consumo }\end{array}$ \\
\hline Aluminio & 721 & 41 & 333 & 23 \\
\hline Bauxita & 13.389 & 88 & 4.996 & 100 \\
\hline Mineral de cromo & 408 & 100 & 875 & 100 \\
\hline \multicolumn{5}{|l|}{ Mincral de cobre } \\
\hline y concentrado & 49 & ( & 2.179 & ( \\
\hline Cobre & 334 & $(17$ & 332 & ( 90 \\
\hline \multicolumn{5}{|l|}{ Mineral de hierro } \\
\hline y concentrado & 36.334 & 32 & 111.519 & 94 \\
\hline \multicolumn{5}{|l|}{ Mincral de plomo y } \\
\hline Plomo & 222 & $(19$ & 5 & $(76$ \\
\hline Mincral de manganeso & 733 & 95 & 2.921 & 90 \\
\hline \multicolumn{5}{|l|}{ Mineral de niquel } \\
\hline y concentrado & 21 & ( & 3.165 & ( \\
\hline Niquel & 119 & ( 90 & 14 & $(100$ \\
\hline Fosfatos & 52 & $\mathrm{a}$ & 3.040 & 100 \\
\hline \multicolumn{5}{|l|}{ Mineral de estaño } \\
\hline y concentrado & 4 & ( & negl. & ( \\
\hline Estaño & 52 & $(100$ & 32 & ( 97 \\
\hline \multicolumn{5}{|l|}{ Mineral de tungsteno } \\
\hline y concentrado & 2,7 & 42 & 2,4 & 100 \\
\hline \multicolumn{5}{|l|}{ Mincral de zinc } \\
\hline y concentrado & 231 & ( & 1.115 & ( \\
\hline Zinc & 484 & $(55$ & 8 & $(80$ \\
\hline
\end{tabular}

"Exportador neto.

ha sido usado extensamente en América Latina y en un menor grado en Australia. ${ }^{30}$

Por otro lado, la ayuda exterior se orienta cada vez más hacia las regiones productoras de recursos naturales que Japón importa. Tokio ha aumentado en forma notable su asistencia técnica y financiera

so"Critical Imported Materials", Op. cit., p. 48. Ver, ađlemás, H. Kanamori, S. Sekiguchi, Y. Murota y Y. Yamanoue, "The Future of the Japanese Economy and its Primary Commodity Requirements", The Japan Economic Reseach Center, Center Paper No 26, March 1975. 


\section{CUADro 5}

IMPORTACIONES JAPONFSAS DE MATERIAS PRIMAS

PRINCIPALFS PROVEEDORES

(Porcentaje del total, 1972)

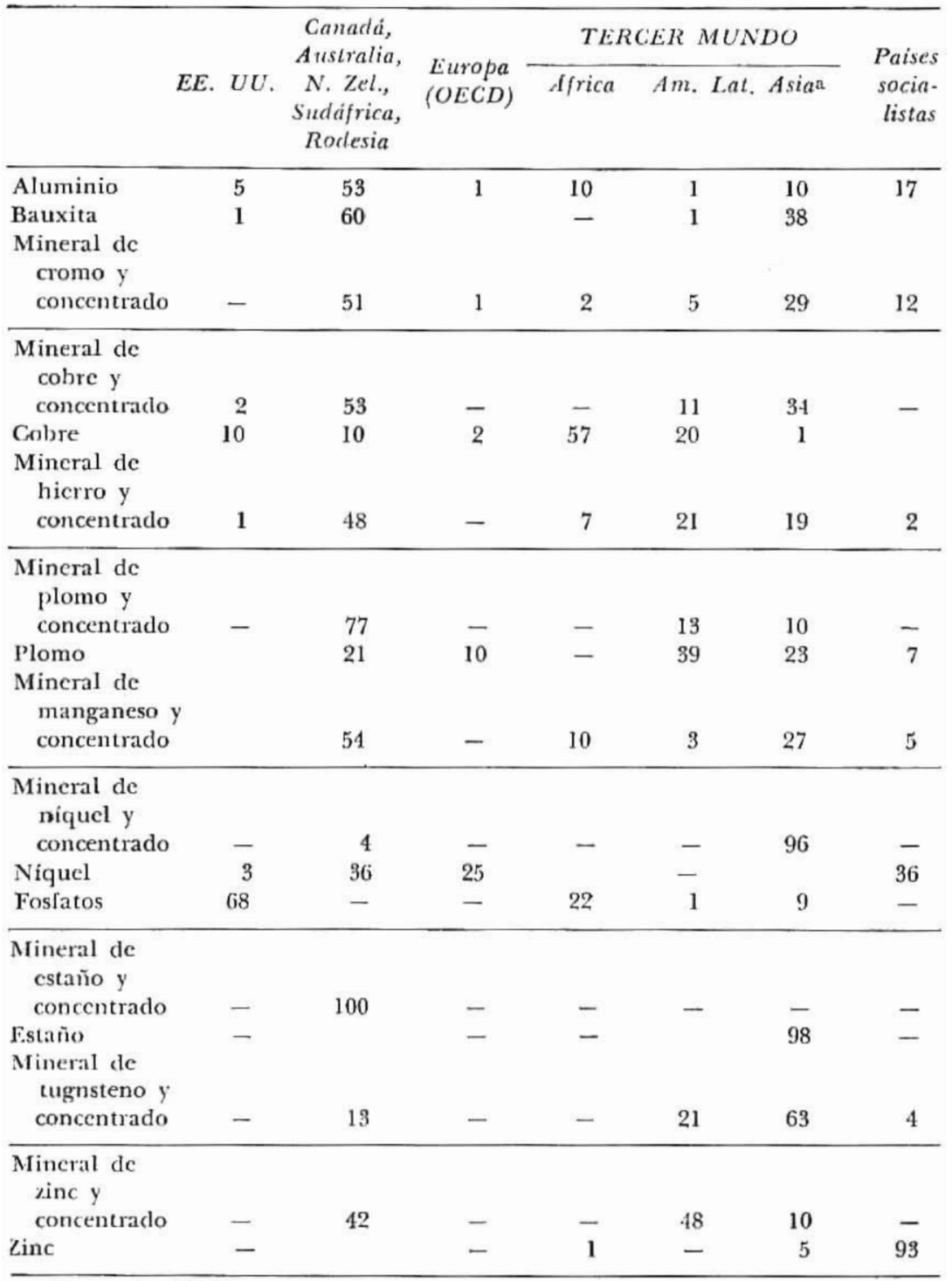

- Menos de 0,5\%.

"Incluye el Medio Oriente y Occanía. 
hacia los países del Medio Oriente, y hacia otros países ricos en minerales tales como Indonesia. También ha iniciado proyectos de cooperación para la construcción de industrias productoras de aluminio en Papua-Nueva Guinea y en Nueva Zelandia; industrias papeleras en Indonesia, Brasil e incluso en la Unión Soviética, y una gran cantidad de refinerías de petróleo, industrias petroquímicas, de fertilizantes y de acero en diversos países del Medio Oriente.

A pesar de todos estos esfuerzos, Japón seguirá teniendo un alto grado de dependencia estratégica. Según el profesor Okita, para EE. UU. es posible considerar una política de autoabastecimiento como el "proyecto Independencia", mientras que para Japón un plan similar significaría una drástica reducción en el nivel de la actividad económica y en el standard de vida de su población. ${ }^{31}$

3) Francia: El grado de dependencia estratégica que experimenta Francia es bastante elevado pero, en todo caso, menor que el de Japón. Francia importa aproximadamente un $100 \%$ del cobre, estaño, zinc, titanio, mercurio y platino que consume; además, depende en un $80 \%$ del exterior para su abastecimiento de plomo. ${ }^{32}$

En el Cuadro 6 que vemos a continuación se observa, en términos globales, el grado de dependencia estratćgica francés comparado con el de otras potencias industrializadas. ${ }^{33}$

Cuadro 6

\begin{tabular}{lcccc}
\hline Materias primas & URSS & EE. UU. & Japón & Francia \\
\hline Recursos mincrales & $5 \%$ & $25 \%$ & $75 \%$ & $60 \%$ \\
Encrgia & $0 \%$ & $10 \%$ & $84 \%$ & $73 \%$ \\
\hline
\end{tabular}

Esta situación de dependencia ha llevado a Francia a iniciar una serie de acciones dentro del ámbito interno y externo, especialmente con posterioridad a la crisis petrolera, tendientes a asegurar su abastecimiento.

El gobierno francés se ha inclinado a apoyar las posiciones reivindicativas de los países pobres productores de materias primas proponiendo acuerdos internacionales con el objeto de asegurar precios

T1Saburo Okita, Op. cit., p. 715.

${ }^{32}$ Ver Général d'Arméc Simon, Matières Premières et Independance Nationale, en "Défense Nationale", Août-Septembre 1974, p. 14.

saver Ibid., p. 12. 
estables y justos para los productores. El interés francés - como ellos mismos han declarado- no es solamente de índole humanitario sino que más bien se encuadra dentro de un plan nacional de seguridad política y económica. De ahí entonces que muchos expertos franceses opinen que cualquiera solución razonable al problema de las materias primas, deberá necesariamente pasar por una repartición de las riquezas entre los países productores del Tercer Mundo y los países industrializados que padecen un alto grado de dependencia estratégica.

4) Alemania Federal: La República Federal es la cuarta potencia industrial del mundo, lo que significa que es una gran consumidora de materias primas. Como la República Federal sólo dispone de un infimo porcentaje de recursos naturales domésticos debe recurrir a la importación para satisfacer la mayoría de las necesidades.

En lo que a petróleo se refiere, alrededor de un $95 \%$ proviene del exterior, siendo el hidrocarburo su principal fuente de energía. Alrededor de un $24 \%$ del consumo primario de energía se cubre con el empleo de carbón producido en el país. Por otra parte, Alemania Federal depende de un $100 \%$ del exterior para su abastecimiento de minerales esenciales tales como el estaño, níquel, fosfatos, platino,

CUADRO 7

DEPENDENCIA ESTRATF́GICA DE ALEMANIA FEDERAL (1972)

(algunos minerales claves)

\begin{tabular}{lrccc}
\hline Materia prima & Unidad & $\begin{array}{c}\text { Producción } \\
\text { doméstica }\end{array}$ & $\begin{array}{c}\text { Producción } \\
\text { Consumo } \\
\text { doméstica en } \\
\text { porcentaje del } \\
\text { consumo }\end{array}$ \\
\hline Petróleo & $\mathrm{mn} \mathrm{t}$ & 7,1 & 134,0 & 5 \\
Cobre & $1.000 \mathrm{t}$ & 1,3 & 524,0 & 0 \\
Plomo & $1.000 \mathrm{t}$ & 38,5 & 326,0 & 12 \\
Zinc & $1.000 \mathrm{t}$ & 122,0 & 435,0 & 28 \\
Estaño & $1.000 \mathrm{t}$ & - & 16,0 & 0 \\
Niquel & $1.000 \mathrm{t}$ & - & 43,0 & 0 \\
Mineral de hierro & $\mathrm{mn} \mathrm{t}$ & 1,7 & 25,0 & 7 \\
Mineral de manganeso & $1.000 \mathrm{t}$ & - & 572,0 & 0 \\
Cromo & $100 \mathrm{t}$ & - & 372,0 & 0 \\
Tungsteno & $1.000 \mathrm{t}$ & - & 6,0 & 0 \\
Molibdeno & $1.000 \mathrm{t}$ & - & 14,0 & 0 \\
Titanio & $1.000 \mathrm{t}$ & - & 457,0 & 0 \\
Bauxita & $1.000 \mathrm{t}$ & 2 & 944,0 & 0 \\
\hline
\end{tabular}

FUENTE: Franz-J. Jägeler, "Inter Economics", No 4, 1974, p. 124. 
Heraldo Muñoz / Dependencia estratégica y no-estratégica

mercurio, uranio y otros. Además, debe importar la mayor parte del mineral de hierro, plomo, cobre, zinc y bauxita. ${ }^{34}$

Como podemos observar en el Cuadro 7, el grado de dependencia estratégica de Alemania Federal es bastante elevado.

En lo que respecta a sus proveedores, Alemania Federal depende de sólo cinco países del Tercer Mundo para el abastecimiento de un $80 \%$ de su petróleo. Sin embargo, como vemos en el Cuadro 8 que incluimos a continuación, el resto de las materias primas proviene de fuentes más variadas y difusas.

\section{Cuadro 8}

IMPORTACIONF.S ALEMANAS POR PAÍSES dE ALgUnOS Minerales Claves (en porcentajes de las importaciones totales)

\begin{tabular}{lccccc}
\hline Petrólec & Libia & Arabia Saudita & Argelia & Nigeria & Irán \\
& 28 & 19 & 11 & 11 & 10 \\
\hline Plomo & Irlanda & Perú & Suecia & Canadá & $\begin{array}{c}\text { Bolivia } \\
\end{array}$ \\
28 & 18 & 17 & 15 & 4 \\
\hline Cobre & Chile & Australia & Bel/Lux. & Zambia & Chipre \\
& 23 & 16 & 7 & 6 & 4 \\
\hline Zinc & Canadá & Suecia & Pcrú & México & Australia \\
& 47 & 13 & 12 & 4 & 2 \\
\hline Estanio & Malasia & Indonesia & Tailandia & G. Bretaña & China \\
& 24 & 23 & 16 & 12 & 1 \\
\hline Bauxita & Australia & Yugoslavia & Sicrra Leona & Grecia & Guayana \\
& 60 & 15 & 9 & 3 & 2 \\
\hline
\end{tabular}

FUeNTE: Franz-J. Jägler, "Inter Economics", No 1974, p. 125.

En resumen, aunque actualmente Alemania Federal tiene un abastecimiento normal de materias primas claves, una interrupción drástica y prolongada de aquel flujo le ocasionaría serios problemas, poniendo así de relieve su alto grado de dependencia estratégica.

De los datos que hemos proporcionado en relación a los cuatro países tratados surgen varios hechos importantes. En primer lugar, las principales unidades económicas del mundo occidental sufren de un grado significativo de dependencia estratégica. En segundo

${ }^{a 4}$ Ver Franz-J. Jägeler, Dependence on Foreign Raw Materials, en "Inter Economics", No 4, April 1974, p. 125. 
a algunas materias primas claves utilizan gran cantidad de derivados del petróleo. De allí que fomentar la producción de sintéticos agudizaría la dependencia estratégica en lo que al hidrocarburo se refiere. Asimismo, existen sustitutos para el petróleo como la energía nuclear -que junto con el poder solar parecen ser las fuentes energéticas del siglo $\mathrm{xxI}$ - pero que, a su vez, como bien dijimos en pp. 79 y ss., utilizan "otras" materias primas tales como el uranio que, a medida que la energia nuclear se transforme en la fuente dominante de generación de electricidad, irá escaseando y profundizando la dependencia estratégica de aquellos países carentes del recurso. ${ }^{3 T}$

Por último, se debe considerar el hecho de que muchos sustitutos artificiales plantean graves problemas al equilibrio ecológico, lo que ha motivado en algunos casos el retorno al uso de materias primas naturales (situación del salitre). En lo que respecta a los sustitutos naturales, a menudo sucede que son tan escasos como el recurso que se desea sustituir o que su oferta está controlada por carteles de productores.

5) Implementación de políticas de reciclaje. Esta alternativa de acción tomaría en la mayor parte de los casos períodos de tiempo bastante extensos. Respecto de algunos minerales (como el aluminio, el cobre y el plomo) el lapso de tiempo sería menor. Por otro lado, en algunos minerales claves la posibilidad de reciclaje es muy baja. En términos generales esta solución resulta antieconómica. El reciclaje se produciría en forma masiva -en los minerales en que ello sea posible- solamente si el precio de la materia prima resulta cxcesivamente alto en comparación con el costo del proceso.

6) Constitución de stocks de reservas estratégicas. Esta estrategia resulta extremadamente costosa. En este caso es al Estado a quien incumbe financiar tal obligación mediante impuestos u otros mecanismos apropiados. EE. UU. es uno de los pocos países que practica sistemáticamente esta política que le puede permitir, en caso de crisis, una mayor maniobrabilidad, por lo menos a corto plazo.

Como podemos observar, las estrategias a disposición de los países industrializados son muy diversas, pudiéndoseles usar en forma separada o de manera conjunta. De todos modos, cada una de estas

${ }^{37}$ Ver "The Nuclear Age", SIPRI, Op. cit., pp. 33-34. 
alternativas implica desventajas que limitan la autonomía y capacidad de respuesta de los países. Sin embargo, el obstáculo más formidable que podría enfrentar la mayoría de estas políticas sería una acción amplia y concertada por parte de los principales países productores de materias primas que apuntara a explotar la dependencia estratégica de los países ricos más vulnerables. ${ }^{38}$

\section{LA OPORTUNIDAD DE LOS PAÍSES EN DESARROLLO}

FRENTE A LA DEPENDENCIA ESTRATÉGICA DE LOS PAÍSES DESARROLLADOS

La creciente subordinación y marginalización de los paises pobres respecto del sistema internacional, y la necesidad de la acción conjunta

La evolución del sistema internacional muestra cada vez con mayor claridad el hecho que los países del Tercer Mundo están sufriendo un proceso de marginalización creciente respecto al avance económico y técnico y, al mismo tiempo, un proceso de subordinación respecto a los países capitalistas desarrollados. ${ }^{39}$

El fenómeno de la marginalización se manifiesta entre otros factores a través de: 1) Un menor ritmo de crecimiento económico relativo en comparación con los países industrializados; 2) Disminución del rol de los países en desarrollo en el comercio internacional; 3) Asignación de un papel secundario a los países del Tercer Mundo en la nueva división internacional del trabajo en lo que se refiere a producción de bienes manufacturados. Es decir, ciertos países en desarrollo, además de ser proveedores de materias primas, comienzan a ser abastecedores de productos manufacturados de menor contenido tecnológico y menor dinamismo, y 4) Persistencia de la clásica situación del cleterioro de la relación de precios de

${ }^{35}$ Una acción de este tipo podría motivar un recrudecer del autoritarismo a nivel internacional por parte de las potencias afectadas. La intervención milita1 parccería ser una alternativa de acción poco probable. Sin embargo, existen otros instrumentos más sofisticados tales como la coacción cconómica. La ley estadounidense sobre reforma del comercio de 1974 es precisamente un ejemplo. La respuesta Iatinoamericana a la ley de comercio consistió en un completo "rechazo político" a una ley que entonces se dirigía a los paises petroleros pero que en el futuro polría apuntar hacia los productores de café, cobre, bauxita u otros.

so" Reunión a nivel de expertos del Comité de Paíscs No Alineados, cncar. gado de analizar el problema de las inversiones privadas extranjeras", Docu. mento preparado per el Gobierno de Chile, Santiago, agosto de 1973, pp. 12-14. 
intercambio entre los países subdesarrollados y los países industrializados.

Por otra parte, la situación de subordinación creciente se refleja a través de algunos hechos como los siguientes: 1) Una proporción creciente del comercio de los países pobres se canaliza hacia los países desarrollados. Al mismo tiempo, sucede que una proporción cada vez mayor del comercio de los países industrializados se efectúa entre ellos mismos; 2) El hecho de que la industrialización de los países en desarrollo se apoya en forma casi exclusiva en tecnologías creadas por los países ricos y en función de condiciones, objetivos y modalidades de crecimiento que le son propias, es un importante factor que consolida y ahonda las relaciones de subordinación de los países en desarrollo vis-à-vis los países industrializados, y 3) Los países subdesarrollados se endeudan respecto a los países desarrollados, a un ritmo varias veces superior al que se desarrollan sus economías. En este sentido cabe destacar que, durante la década del 60 , la deuda externa de los países pobres creció a un ritmo anual de un $12 \%$, en circunstancias de que el producto per cápita de los mismos creció apenas a algo más del $2 \%$.

Este proceso simultáneo de subordinación y marginalización de los países subdesarrollados a que nos hemos referido, ha significado un aumento del grado de concentración del poder económico en los países ricos. Uno de los factores principales de este desarrollo asimétrico ha sido justamente uno de los puntos mencionados anteriormente, es decir, la tendencia desfavorable de la relación de intercambio de los países en desarrollo.

Desde mediados del decenio de 1950 hasta fines de la década del 60 los precios medios de las exportaciones de los países subdesarrollados, excluidos los que exportan petróleo, no registraron ningún aumento, mientras que los precios de las exportaciones de los países capitalistas desarrollados aumentaron constantemente, principalmente como consecuencia de las continuas presiones inflacionarias en esos países. En consecuencia, durante ese período la relación de intercambio de los países en desarrollo sufrió un empeoramiento del orden del $12 \%$. Una disminución semejante, del $10 \%$, también se produjo en la relación de intercambio de los principales países exportadores de petróleo ${ }^{40}$. En el Cuadro № 9 se puede apreciar claramente las variaciones en los precios de las exportaciones e importaciones y de la relación de intercambio de los países subdesarrollados, durante el período 1954-1972.

${ }^{40}$ Ver "Los Problemas de las Matcrias Primas y el Desarrollo", Informe del Sccrctario Gencral de la UNCTAD preparado para el sexto periodo extraordinario de sesiones de la Asamblea General, Nacional Unidas, Nueva York, 1974, p. 2. 


\section{Cuadro 9}

VARIACIONES DE LOS PRECIOS DE LAS EXPORTACIONES E IMPORTACIONES* Y DE LA RELACIÓN DE INTERGAMBIO DE LOS PAÍSES EN DESARROLLO, 1954 a 1972

\begin{tabular}{|c|c|c|c|c|c|c|}
\hline & $\begin{array}{l}\text { Precios de } \\
\text { las expor- } \\
\text { taciones }\end{array}$ & $\begin{array}{c}\text { Precios de } \\
\text { las impor- } \\
\text { taciones }\end{array}$ & $\begin{array}{l}\text { Relacion } \\
\text { de inter- } \\
\text { cambioc }\end{array}$ & $\begin{array}{l}\text { Precios de } \\
\text { las expor- } \\
\text { taciones }\end{array}$ & $\begin{array}{l}\text { Precios de } \\
\text { las impor. } \\
\text { taciones }\end{array}$ & $\begin{array}{l}\text { Relación } \\
\text { de inter- } \\
\text { cambio }^{\mathrm{c}}\end{array}$ \\
\hline & \multicolumn{6}{|c|}{ (En porcentaje) } \\
\hline $1954-56$ a & & & & & & \\
\hline $1968-70$ & +2 & +13 & -10 & -1 & +12 & -12 \\
\hline $1968-70 \mathrm{a}$ & & & & & & \\
\hline 1972 & +39 & +17 & +19 & +12 & +17 & -5 \\
\hline $1954-56$ a & & & & & & \\
\hline 1972 & +42 & +33 & +7 & +11 & +32 & -16 \\
\hline
\end{tabular}

"Expresados en dólares de los Estados Unidos.

'Basados en las variaciones de los ingresos (incluidos regalias e impuestos) por bartil de petróleo crudo exportado.

'Relación entre los precios de las exportaciones y los precios de las importa ciones.

FUENTE: Estimaciones de la secretaria de la UNCTAD.

Esta situación de deterioro que hemos examinado se ve agravada por las operaciones de las grandes empresas multinacionales, las cuales, gracias a su enorme poder de negociación como compradores monopolísticos u oligopolísticos, pueden muchas veces adquirir los productos primarios de los países subdesarrollados a precios inferiores a los que se obtendrían aun en un mercado puramente competitivo.

Cabe destacar que hacia fines de 1972 la tendencia desfavorable en la relación de intercambio de los países en desarrollo sufre un cambio importante ${ }^{41}$. Esta tendencia se ve reforzada con el brusco movimiento alcista del petróleo, motivado por la crisis de octubre de 1973. El auge de los precios de las materias primas reportó mayores beneficios a los países desarrollados exportadores de productos básicos que a los países en desarrollo, ya que las ventajas temporales obtenidas por algunos de estos últimos se vieron notablemente dis-

"Conviene destacar que los aumentos de precios de las matcrias primas se debieron, en medida considerable, a una escasez temporal de ciertos productos básicos a consecuencia de factores climáticos, y de otra indole, quc coincidicron con una aceleración extraordinariamente rápida de la demanda. 
minuidas a causa de la inflación y de la recesión económica de los países industrializados. En todo caso, a mediados de 1974 los precios de aquellas materias primas, exceptuando el petróleo, sufrieron un colapso repentino que enfrió el optimismo de quienes pensaban en una virtual desaparición de las tendencias de largo plazo al deterioro de las relaciones de intercambio, o en una reivindicación del esquema clásico de la división internacional del trabajo entre productores de manufacturas y productores de bienes primarios.

\section{Hacia una estrategia racional de enfrentamiento}

La continuada inestabilidad de los mercados de productos básicos, la persistente inflación y la baja acelerada de los precios de las materias primas después del breve auge registrado en el período 1972-74 ha motivado una movilización general de los países productores del Tercer Mundo para transformar las estructuras del comercio mundial y establecer un nuevo orden económico internacional.42

Por otro lado, la crisis petrolera ha conducido a una mayor toma de conciencia por parte de los países subdesarrollados sobre la necesidad de implementar en forma efectiva una serie de principios tales como la soberanía de los pueblos sobre sus recursos naturales, y de su derecho a explotarlos, y el logro de precios justos para sus exportaciones. En suma, el problema de los productos básicos se ha convertido en un elemento cada vez más decisivo de las relaciones políticas y económicas internacionales.

En este contexto, los países en desarrollo, agrupados en diversos organismos como el Grupo de los 77, han recomendado una serie de medidas tendientes a acabar con las disparidades de riqueza entre los países desarrollados y subdesarrollados. Entre otras recomendaciones figuran las siguientes: ${ }^{43}$

\footnotetext{
"2Existe una gran cantidad de declaraciones y artículos accrca de la emergencia del nuevo orden. Ver, por ejemplo: "Declaración Solemne de la Conferencia de los Soberanos y Jefes de Estado de los países miembros de la OPEP", Argel, OPEC/5.1/1/Rev. 1, marzo 1975; Carta del Presidente de V'enczulela al Presidente de los Estados Unidos de América, en "Comercio Exterior", México, octubre de 1974; Sheikh Ahmed Zaki Yamani. Oil: Towards a new producerconsumer relationship, "The World Today", Chatham House, November 1974; Declaración sobre el establecimiento de un nuevo orden econónico internacional y programa de acción, "ONU-Crónica Mensual", Naciones Unidas, Vol. XI, No 5 , mayo de 1974; Carta sobre los Derechos y Deberes Económicos de los Estados, "Comercio Exterior", México, D, F., Suplemento de diciembre 1974.

${ }^{4}$ Ver "Informe de la Comisión de Productores Básicos sobre su Octavo Período de Sesiones", Junta de Comercio y Desarrollo, $15^{\circ}$ periodo de sesiones, Ginebra, 12 de marzo de 1975 , p. 4.
} 
1) Implementación de mediclas inmediatas para promover la trans. formación de los productos primarios en los mismos paises en que se producen.

2) Eliminación de todas las barreras al comercio de las materias primas en sus formas bruta y elaborada.

3) Garantías a los países en desarrollo de una parte cada vez mayor del comercio mundial de manufacturas y semimanufacturas mediante esquemas de preferencia y la reconversión de las estructuras de producción en los países desarrollados.

4) Aumento de las transferencias financieras netas de los países desarrollados a los países en desarrollo hasta que alcancen el $1 \%$ del P. N. B. para finales de 1975.

5) Ampliación de las actividades de investigación y desarrollo relacionados con las materias primas naturales producidas por los países en desarrollo.

6) Apoyo a los esfuerzos de los países en desarrollo para reforzar el comercio y la cooperación entre ellos.

Además de estas propuestas, han surgiclo otras alternativas de acción como la que pretende organizar un "sistema de reservas" de una serie de productos básicos. La constitución de reservas a nivel internacional para una amplia gama de productos permitiría estabilizar y fortalecer los precios de los productos básicos. Estas reservas serían financiadas por medio de un fondo común que aún no ha sido adecuadamente definido. Por otra parte, se ha sugerido la aplicación del principio de la "indización" que consiste en vincular los precios de las materias primas con los precios mundiales de las manufacturas. La indización sería un complemento esencial de un programa integrado sobre los productos básicos. No obstante, incluso los países en desarrollo reconocen que no se podría aplicar una fórmula única de indización, en vista de las diferencias existentes entre los países subdesarrollados tanto en lo que respecta a las estructuras de importación como a sus necesidades de crecimiento y diversificación. ${ }^{44}$

Ahora bien, teniendo como telón de fondo la dependencia estratégica de los países industrializados creemos necesario introducir un enfoque global de los problemas de las materias primas que apunte

"Ibid., pp. 30-33 y pp. 43-46. Ver, además, Raw Materials: Smoothing out the wild swing, en revista "Time", June 16, 1975, pp. 48-49. 
a implementar lo que hemos denominado una "estrategia racional de enfrentamiento".

Esta estrategia debe apuntar a explotar la debilidad de los países ricos representada en la situación de dependencia estratégica, y deberá basarse en una acción cooperativa entre los países del Tercer Mundo, mediante la creación de organizaciones de países productores y exportadores, la cooperación regional y el control sobre los mecanismos de precios.

Las iniciativas tomadas por los países miembros de la OPAEP señalan el camino que el resto de países productores del Tercex Mundo debe seguir para controlar y valorizar sus recursos nacionales, y constituyen un ejemplo del principio de solidaridad entre las naciones en desarrollo. En último término creemos que los pueblos de América Latina, Africa y Asia tendrán que contar consigo mismos y con sus propios recursos para asegurar su desarrollo.

Como ya hemos indicado anteriormente, los países en desarrollo del Tercer Mundo producen alrededor de un $65 \%$ de la producción de bauxita del mundo no-socialista, un $93 \%$ del mineral de estaño, alrededor de un $50 \%$ del cobre, un $89 \%$ del manganeso, $95 \%$ del cromo, $84 \%$ del cobalto y cerca de un $40 \%$ de los fosfatos naturales, todos estos minerales claves para la seguridad de los países industrializados. En consecuencia, un primer paso de la estrategia deberá ser la constitución de carteles de productores de los minerales mencionados. Al mismo tiempo deberá buscarse el apoyo y la cooperación de países desarrollados exportadores de materias primas tales como Australia y Canadá que muy probablemente responderían en forma positiva. Sin embargo, es necesario distinguir entre un alza unilateral de los precios de un producto básico dado y un embargo o interrupción del abastecimiento del mismo. La posibilidad de obtención de apoyo de países como Canadá y Australia será mayor en la medida que se utilice la primera alternativa.

La segunda etapa de la estrategia sería la creación de una Organización Central Coordinadora de los Carteles de Productores. Este organismo se encargaría de coordinar las acciones de los diversos carteles de productores del Tercer Mundo, y se ocuparía de presionar a los países industrializados con el objeto de negociar arreglos que beneficien a todas las materias primas en conjunto. En este sentido la Organización institucionalizaría la política introducida por el Presidente de Venezuela Carlos Andrés Pérez de discutir, en cualquiera conferencia internacional sobre energía, no sólo el tema del petróleo sino el de todas las materias primas en general. ${ }^{45}$

\footnotetext{
${ }^{45}$ Esta alternativa ha sido resistida por los países desarrollados, especialmente por EE. UU. que sostiene -a través de su Secretario de Estado Henry Kissin. ger- que cl problema de las materias primas debe ser tratado en base a un
} 
Ahora bien, la "estrategia racional de enfrentamiento" debe buscar arreglos mediante el uso intensivo del diálogo y la negociación. Sin embargo si el diálogo resultase infructífero deberá utilizarse el arma del boicot o embargo de las materias primas claves. Estos boicots deberán apuntar hacia los países industrializados con más alto grado de dependencia estratégica y deberán ser coordinados y apoyados por la Organización Central. Al mismo tiempo, se deberán decretar embargos temporales de otras materias primas claves que puedan servir como sustitutos. Por ejemplo, un embargo del cobre deberá ir acompañado de un embargo de apoyo de los productores de bauxita y, si es posible, por el boicot parcial de otros minerales con el objeto de aumentar la presión y la efectividad del embargo original.

Mientras durase el boicot, la Organización Central otorgaría ayuda financiera a los países más afectados por la reducción de las exportaciones, de lo que se desprende que la Organización deberá tener un Fondo Financiero Común derivado de aportes provenientes de los países productores miembros. Las contribuciones deberán ser obviamente mayores en el caso de los paises petroleros. Asimismo la Organización otorgaría préstamos a países subdesarrollados no-miembros, es decir, a aquellos países pobres y, además, carentes de materias primas importantes.

Cabe destacar que algunos autores sostienen que ningún otro cartel del Tercer Mundo podría alcanzar el grado de solidaridad política existente en la OPEP. Sin embargo, a pesar de las diferencias ideológicas, raciales, culturales, geográficas, etc., prevalecientes entre los diversos países productores del Tercer Mundo, también existe una identidad común respecto de sus riquezas naturales que se manifiesta en algunas demandas específicas comunes tales como la soberanía de los pueblos sobre sus recursos naturales y su derecho a explotarlos y la obtención de precios justos para sus exportaciones. Hay una serie de elementos poco tangibles que unen a países productores tan radicalmente diferentes como Chile y Zambia, Venezuela e Irán, Ecuador y Nigeria. Lo mismo podría decirse de la supuesta afinidad existente entre los miembros de la OPAEP. Desde el punto de vista político, ¿̇cuáles son los elementos comunes entre una república con un gobierno revolucionario como el de Argelia y una monarquía semifeudal como la de Arabia Saudita? Objetivamente parecen ser muy pocos. De aquí se desprende entonces que la posibilidad de cooperación y solidaridad se funda en el deseo de alcanzar una auténtica independencia política y económica a través de la defensa

enfoque "caso por caso". Por otra parte, el Primer Ministro británico Harold Wilson es partidario de estabilizar los precios de por lo menos 11 productos básicos para así evitar los efectos imprevistos de las fluctuaciones. 
de los recursos naturales antiguamente explotados por las potencias industrializadas de Occidente. ${ }^{46}$

Inspirados en el éxito de la OPEP varios países productores de materias primas del Tercer Mundo se han asociado en carteles de productores para exigir un precio mínimo a sus exportaciones. Un grupo de países productores de café -apoyados por Venezuela- ha exigido el establecimiento de un precio mínimo mundial (65 dólares por cada saco de 100 libras) o impondrán un embargo a sus exportaciones si no logran su objetivo. Los países integrantes del CIPEC han reducido sus exportaciones de cobre en más de un $10 \%$ buscando metas similares. No obstante, estos esfuerzos aislados no han dado resultado. En cierta medida la verdadera repercusión de estas acciones se hará sentir cuando la economía mundial -y por tanto la demanda por materias primas- salga del actual período de recesión. Sin embargo, lo más importante es que estas iniciativas aisladas deberán - para lograr resultados significativos- enmarcarse dentro de una estrategia general como la que hemos descrito en los párrafos anteriores.

Al implementar esta estrategia los países subdesarrollados estarían jugando de acuerdo a las mismas reglas usadas por los países desarrollados para el fomento de su propio crecimiento económico, es decir, las leyes de la oferta y la demanda y su interdependencia. En todo caso, la ejecución de boicots por parte de la Organización Central tiene muchos precedentes. Las compañías monopólicas de los países ricos, por ejemplo, llevaron a cabo boicots muchas veces exitosos en contra de aquellos países pobres que osaban recuperar su riqueza nacional. Fue lo que sucedió en México cuando el Presidente Lázaro Cárdenas decidió nacionalizar el petróleo. Un fenómeno similar se produjo con motivo de la nacionalización del petróleo llevada a cabo por Irán en 1951, y con la expropiación de las compañías francesas en Argelia el año 1971. Por último, los japoneses todavía recuerdan los efectos nocivos causados por el boicot de la semilla de soya efectuado por EE. UU. en 1973. La historia reciente abunda en ejemplos de países que han sufrido o sufren boicots, o sanciones económicas en general. Ninguno de esos países se desplomó ante la "presión aislada" de los embargos, pero el desorden causado a sus economías y la amenaza a su seguridad nacional no fueron menos ciertos. En consecuencia, la existencia de una alta dependencia estratégica por parte de muchos paises industrializados abre mayores po-

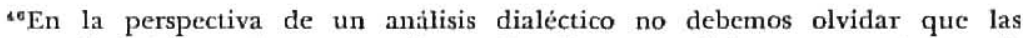
alianzas de paises productores en dcsarrollo sólo son posibles en general a partir de una modificación sustancial de la estructura doméstica de poder de cada nación, desplazando del gobierno a los grupos incapaces de enfrentarse consccuentemente con el imperialismo. 
sibilidades de éxito a una estrategia racional de enfrentamiento como la que hemos descrito.

Dicha estrategia de confrontación será racional en la medida en que suponga un conocimiento adecuado de los límites de quienes son débiles. Por lo tanto el enfrentamiento no excluye el diálogo. Por el contrario, como ya hemos visto, éste debe preceder a aquél. Lo que sí debe quedar en claro es que los países del Tercer Munclo están pasando por una coyuntura histórica favorable que no debe ser desaprovechada. Es incuestionable que la crisis del petróleo ha mejorado la capacidad de negociación de los productores primarios. De unos más, de otros menos, pero en su conjunto -y dependiendo de la estrategia que adopten- las economías de la periferia se sentarán, en el futuro, antes las mesas de negociación con cartas más poderosas y respetadas que en el pasado.

UNA OBSERVACIÓN FINAL

Sin lugar a dudas vivimos en un mundo cada día más interdependiente. No obstante, esta creciente interdependencia conlleva el peligro de la perpetuación y afianzamiento de una estructura económica internacional que deje a los paises en desarrollo en una posición cada vez más dependiente (dependencia global) de las potencias industrializadas, a menos que aquéllos sepan aprovecharse de la situación de "dependencia estratégica" (dependencia sectorial) de los países ricos.

Lo que aquí propugnamos entonces es la implementación de una "estrategia racional de enfrentamicnto" que precisamente apunte a explotar la debilidad relativa de los países desarrollados, y que además sirva para realizar la verdadera independencia económica y política de los países pobres.

Inspirados y alentados por el empleo del arma del petróleo los países exportadores de materias primas deberán crear nuevas organizaciones destinadas a proteger los recursos nacionales y a defender los precios de las materias primas. Consecuentemente, la unidad, la ayuda mutua y la coordinación en la lucha contra la explotación se constituirán en elementos claves de la estrategia ya mencionada.

Esta estrategia en último término favorecerá la integración mundial en la medida en que la libertad y la igualdad de los pueblos oprimidos son precisamente prerrequisitos para la integración. Como bien ha dicho Gunnar Myrdal: "Solamente cuando todas estas naciones desprivilegiadas, con sus grandes multitudes de habitantes con 
rasgos raciales, color de piel, religiones, folklores y herencias culturales diferentes, obtengan igualdad de oportunidades, el mundo llegará a integrarse".47

La alternativa a la subordinación de los países en desarrollo consiste en un cambio fundamental de las relaciones sociales y de producción. Cada nación deberá encontrar su propio camino en la búsqueda de tal objetivo. Obviamente, dicha vía tendrá que ser determinada por la estructura social y económica, la experiencia histórica y la idiosincrasia de cada país. No obstante, en la lucha contra la dominación externa, la unidad y la solidaridad entre los países dependientes son principios básicos e ineludibles.

Los pueblos del Tercer Mundo no permitirán que coexistan indefinitivamente la pobreza y la opulencia. No aceptarán un orden internacional que perpetúe su atraso. De ahí que la actual coyuntura internacional -en la perspectiva de la dependencia estratégica de los ricos- aparece particularmente favorable a la introducción de cambios transcendentales en la tradicional relación centro-periferia.

${ }^{47}$ Gunnar Myrdal, citado por Rupert Emerson, "From Empire to Nation" (Beacon Press, Boston, 1970), p. 396. 